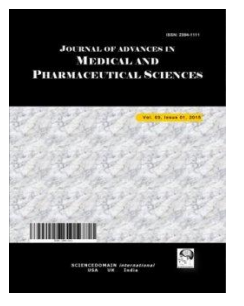

\title{
Protein Syntheses in Epithelial-mesenchyme Transitions as Markers of Platelet-induced Cultured Cancer Cell Proliferation
}

\begin{abstract}
Brian J. Poindexter ${ }^{1}$, Lenard M. Lichtenberger ${ }^{2}$, Dexing Fang ${ }^{2}$ and Roger J. Bick ${ }^{1 *}$

${ }^{1}$ Department of Pathology and Laboratory Medicine, The University of Texas Health Science Center, McGovern Medical School, Houston, TX 77030, USA.

${ }^{2}$ Department of Integrative Biology and Pharmacology, The University of Texas Health Science Center, McGovern Medical School, Houston, TX 77030, USA.

Authors' contributions

This work was carried out in collaboration between all authors. Authors RJB and BJP designed the study, performed the imaging and statistical analysis. Authors $L M L$ and DF cultured the cells and performed the treatments strategies. All authors had input as to the content and construction of the manuscript. Author $L M L$ is the PI of the aspirin-based research program. Authors RJB and LML managed the literature searches. All authors read and approved the final manuscript.
\end{abstract}

Article Information

DOI: 10.9734/JAMPS/2017/34071

Editor(s):

(1) Amr Ahmed El-Arabey, Pharmacology \& Toxicology Department, Al-Azhar University, Egypt \& University of Science and Technology of China (USTC), China.

Reviewers.

(1) Yahay Elshimali, University of California, Los Angeles, USA.

(2) Asya Dragoeva, University of Shumen, Bulgaria. Complete Peer review History: http://www.sciencedomain.org/review-history/19551

Original Research Article

Received $12^{\text {th }}$ May 2017

Accepted $10^{\text {th }}$ June 2017

Published $15^{\text {th }}$ June 2017

\section{ABSTRACT}

Aims: To study the changes in protein content and protein patterns in platelet activated epithelialmesenchymal transition of cultured colon cancer cells.

Place and Duration of Study: UT McGovern Medical School, Houston, Texas, USA. Between May, 2015 and May, 2017.

Methodology: Mouse platelets were added to cultured colon cancer cells and fluorescence deconvolution microscopy was performed with image acquisitions being stacked, volume rendered and modeled to yield protein localizations, quantity and patterns.

Results: Studies identified and localized proteins involved in cell transitions. Co-culturing resulted 
in an increased cell number, increased cell size and increased protein content. Fibronectin content was increased to a greater extent than laminin; G-actin content was also increased indicating upregulation of synthesis, and the fibroblastic-type cells were much longer with the fibronectin containing fibrillar extensions suggesting increased adhesion was occurring. Greater fibronectin than laminin synthesis indicates cells undergoing a change to matrix protein form rather than a basement membrane, polarized epithelial cell type, observations which suggest platelet activation endows the cells with adhesion and invasion abilities.

Conclusions: The study showed that platelet activation of cancer cells drives endothelial cells into a matrix-compatible mesenchymal form and that the epithelial to mesenchymal transition occurs when surface cells lose polarity and cell-cell adhesion properties. These cells become migratory and invasive for rapid and facilitated cancer progression, due to enhanced adhesion and synthesis of specific proteins and cell extensions.

Keywords: Fluorescence microscopy; cell transitions; cancer; matrix proteins.

\section{INTRODUCTION}

In 1992 a review discussed the role of platelets in the spread of cancer, noting "a highly coordinated and dynamic multistep process in which cancer cells undergo extensive interactions with host cells before they establish a secondary metastatic colony" [1]. Prior to that publication, research was published which concluded that adhesive glycoproteins were intimately involved in cancer cell invasion and metastasis, and that laminin and fibronectin promoted cell adhesion and motility [2]. Despite more than thirty years' worth of data showing that particular proteins are involved in the spread of cancer cells, and that endothelial-mesenchymal transition (EndoMT) and epithelial-mesenchymal transition (EMT) are valuable targets for therapeutic interventions in many diseases $[3,4,5]$, less success than was hoped for has been forthcoming in developing interventional strategies.

Research has demonstrated that platelets interact with circulating tumor cells (CTC) directly, as well as in a neutrophil-fibrin associated network, thereby prolonging the halflife of CTC's [6]. Platelets have also been reported to trigger EMT of cancer cells $[7,8,9]$ and increase the adhesion of metastatic hepatoma cells to the extracellular matrix [10], an important factor when deciphering cell invasion mechanisms and a focus of this study. However, while cells can undergo EMT, they have to be able to invade underlying tissues, and this involves having the ability to pass through cellcell adhesions such as tight junctions and desmosomes [11] and penetrate the basement membrane and underlying extracellular matrix [12]. It is therefore not surprising that mesenchymal-cell types initiate mechanisms to facilitate penetration, including the synthesis of necessary proteins such as laminin and fibronectin which, as stated above, increase adhesion and cell mobility and so this indicates that this is an important step in achieving invasion which is up-regulated by platelets.

Work in this lab is partly focused on halting cell proliferation and we noted that not only was there a perinuclear localization of, and increased amounts of proteins in, cultured cancer cells following platelet activation, but that there were particular protein patterns before and after platelet treatment. We microscopically imaged fibronectin and laminin to detail their distributions, and compare quantities in control versus platelet activated cultures, during cell transition into a mesenchymal form. This was based on reports that noted the need for epithelial detachment, basement membrane changes, cell migration and protein rearrangements [13] for endothelial cells to develop the ability to adhere and invade into tissues. Further, an earlier study suggested that a down regulation of laminin production, coupled with increased fibronectin synthesis, was intimately involved in the transition from epithelia to invasive fibroblastic cells [14].

Thus, a comprehensive knowledge of this multifaceted and dynamic process is required in understanding developmental and disease processes and constructing protocols to devise appropriate therapies [15].

\section{MATERIALS AND METHODS}

\subsection{Animals and Blood Products}

Mice were maintained as required by the Animal Welfare Committee (AWC) and the Institutional 
Animal Care and Use Committee (IACUC) for The University of Texas Health Science Center at Houston (UTHealth-McGovern Medical School). Young adult male BALB/c mice (20-24 g; Envigo, Houston, Tx, USA), were supplied and housed in the Center for Laboratory Animal Medicine \& Care (CLAMC) facility at UTHealth.

\subsection{Cancer Cells}

Murine colon cancer cells (MC-26) were obtained from the $\mathrm{NIH}$ National Cancer Institute (Bethesda, MD, USA). Cells were cultured in the suggested growth medium with $10 \%$ fetal bovine serum (Sigma-Aldrich, St. Louis. MO). Tests for mycoplasma were negative (conducted with the MycoAlert Mycoplasma Detection Kit from Lonza, Rockland, ME, USA).

\subsection{Chemicals and Reagents}

All chemicals, buffers, and cell culture media were purchased from Sigma-Aldrich unless otherwise noted. Matrigel Membrane Matrix (354234) was from Corning (Tewksbury, MA).

\subsection{Human and Mouse Platelet Isolation}

Human blood from healthy fasting donors was drawn into acid: citrate: dextrose (ACD) anticoagulant at a 1:9 ratio ( $\mathrm{vol} / \mathrm{vol})$ as previously described [16]. Platelet rich plasma (PRP) was prepared by centrifuging blood at $200 \times \mathrm{g}$ for 15 minutes at room temperature (RT), and the PRP was supplemented with $75 \mathrm{nM}$ of $\mathrm{PGE}_{1}$, and centrifuged at $1000 \times \mathrm{g}$ for 10 minutes at RT to obtain a platelet pellet that was re-suspended and washed with CGS buffer (13mM sodium citrate, $30 \mathrm{mM}$ glucose, $120 \mathrm{mM}$ sodium chloride, $\mathrm{pH} 7$ ) in Minimal Essential Media (MEM). Counts were adjusted to $2.5 \times 10^{8}$ platelets $/ \mathrm{ml}$. Mouse blood $(B A L B / c)$ was collected from the inferior vena cava of isoflurane-anesthetized animals into $A C D$ at a ratio of $1: 10(\mathrm{vol} / \mathrm{vol})$ and then blood was diluted 1:1 with PBS. PRP was prepared by centrifugation at $68 \times \mathrm{g}$ for 10 minutes and washed platelets were harvested as previously described [17], then re-suspended in RPMI-1640 (ThermoFisher Scientific, Waltham, MA, USA) with $0.01 \mathrm{U} / \mathrm{ml}$ of apyrase at a concentration of $2.5 \times 10^{8}$ platelets $/ \mathrm{ml}$.

\subsection{Co-culture of Cancer Cells and Washed Platelets}

In studies to assess EMT activity, MC-26 cancer cells were co-cultured with washed mouse platelets (mWPs) at a ratio of $1: 400$ at $37^{\circ} \mathrm{C}, 5 \%$ $\mathrm{CO}_{2}$ for 18-24 hours. The cultured cells were washed with phosphate buffered saline (PBS) and then lysed with RIPA buffer (Fisher Scientific, Waltham, MA) for vimentin, Ecadherin, and fibronectin Western blots. For immunofluorescence staining, the MC-26 cells were co-cultured with mWPs at a ratio of 1:400 on 18-mm cover slips for 18-24 hours.

\subsection{Immunofluorescence}

Cultured cells on coverslips were fixed in $4 \%$ formaldehyde, permeabilized by incubation in $0.5 \%$ Triton $X-100$, blocked with $10 \%$ goat serum, then stained with polyclonal antifibronectin (Sigma-Aldrich, St. Louis, MO, USA) followed by Alexa-647 conjugated goat antirabbit antibody (Molecular Probes/Invitrogen, Thermo Fisher Scientific, Waltham, MA, USA). Subsequently the samples were stained for $f$ actin, g-actin by Alexa Fluor ${ }^{\circledR} 488$ phalloidin and the nuclei by DAPI (Invitrogen, Carlsbad, CA) and finally mounted on slides with elvanol antifade (DuPont, Carlsbad, CA, USA). Specimens were visualized by Fluorescence Deconvolution Microscopy employing an Olympus IX-70 microscope connected to a DeltaVision imaging system (Applied Precision, Issaquah, WA, USA) and quantitation of immunofluorescence was made using pixel densities as previously described [18].

\section{RESULTS}

\subsection{Platelets Induce Proliferation of Colon Cancer Cells}

We assessed the stimulatory effect of platelets on the growth of a commercially available line of colon cancer cells from mouse (MC-26 cells) and Fig. 1 shows that platelets stimulate cell growth and synthesis of fibronectin (red, top panels) and laminin (red, lower panels). Note the increased number and 'exaggerated' spindle-like form of the cells following platelet co-culture.

Platelets have the ability to promote both the invasive potential and EMT transition of cancer cells [9], and in a previous publication [19], we investigated the effects of platelets on the invasive ability of cultured cancer cells. There was a $\sim 20$-fold increase in the number MC-26 cells which crossed membranes from upper to lower chambers of a 48-well culture plate following platelet 'treatment'. Also, as platelets 
have been reported to initiate a morphological change in cancer cells accompanied by increased production of fibronectin and formation of a fibronectin-associated, extracellular microfilamentous network, we imaged both protein formation and cell form before and after platelet initiated transition.

Fig. 2 shows a rather bulbous control cancer cell (image A) compared to a long, slender, mesenchymal-like, platelet treated cell (image B). Probing these cultures for laminin and fibronectin content in the cultures revealed dramatic increases in protein, with more than a doubling of the protein content in platelet treated cells.

To gain further insight into protein formation and adhesive abilities of transformed cells, the nucleus and peri-nuclear areas of some cells were imaged and modeled to see organellar distribution of the proteins. Fig. 3 shows a high red/orange intensity in a perinuclear area in cells co-cultured with platelets (high magnification cutout also shown), likely the golgi and endoplasmic reticulum, while some extracellular fibronectin can also be seen. Modeling of protein to yield an image with a greater degree of clarity as to intracellular locations was performed as before [20,21].

To produce a specific image of protein distribution and content, Fig. 4 shows channel splitting of control (A and $\mathrm{C}$ ) and platelet cocultured cells ( $B$ and $D)$, with black circles indicating areas of adhesion in images $A$ and $B$, couple with arrows indicating long fibronectin fibers in the platelet-added culture (B). When the images were mapped with the specific probe wavelength assigned to the protein (lower red images; images $C$ and D), the control cells do not to have fibronectin in some adhesion areas $(C)$, unlike the platelet treated culture (D) which has a copious amount of fibronectin in areas of stellate projections (white circles).

Finally, to further demonstrate fibronectin 'mapping', Fig. 5 shows high magnification cutouts of a cultured cell image (Panel A) versus platelet activated cells (Panel B). Note the extracellular extensions (white arrows; Panel B), while most of the fibronectin in Panel $A$ is intracellular.

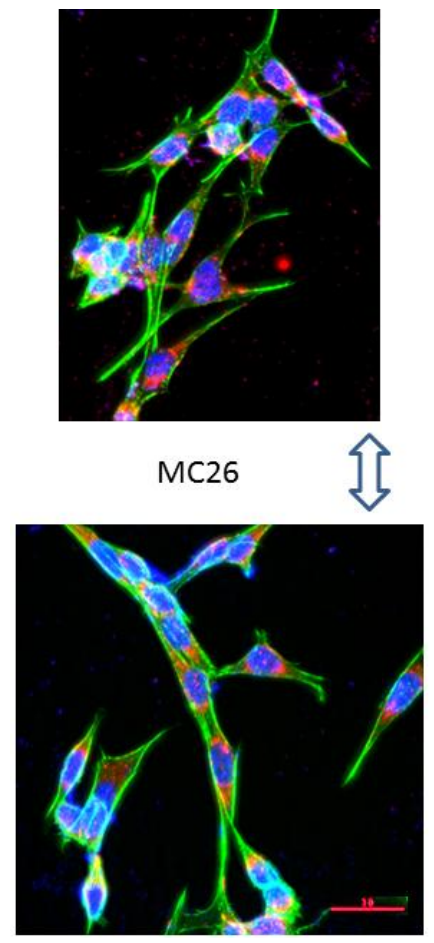

\section{Fibronectin=red Nuclei=blue(DAPI) $\mathrm{F}$-actin $=$ green}

Laminin=red Nuclei=blue(DAPI) $\mathrm{F}$-actin $=$ green
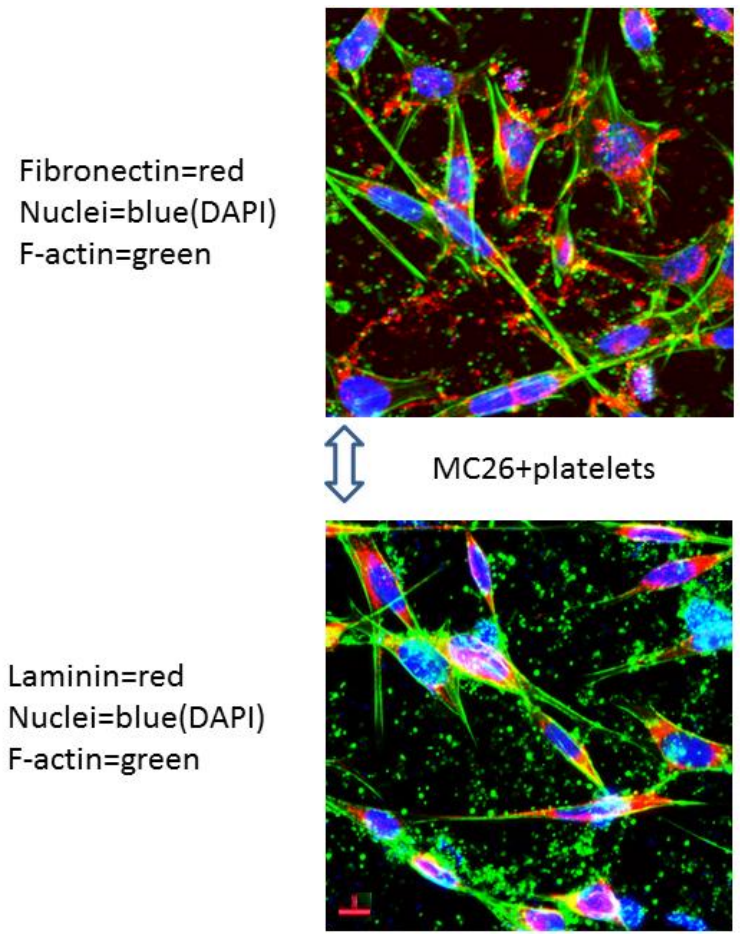

Fig. 1. Effect of platelets on cell growth showing platelet stimulation of MC 26 cell growth and increased synthesis of fibronectin (red, top two panels) and laminin (red, lower two panels) Note the increased number and 'exaggerated' spindle-like form of the cells following platelet co-culture. Antibodies and image acquisitions as detailed in Results section (mag. $x$ 600) 


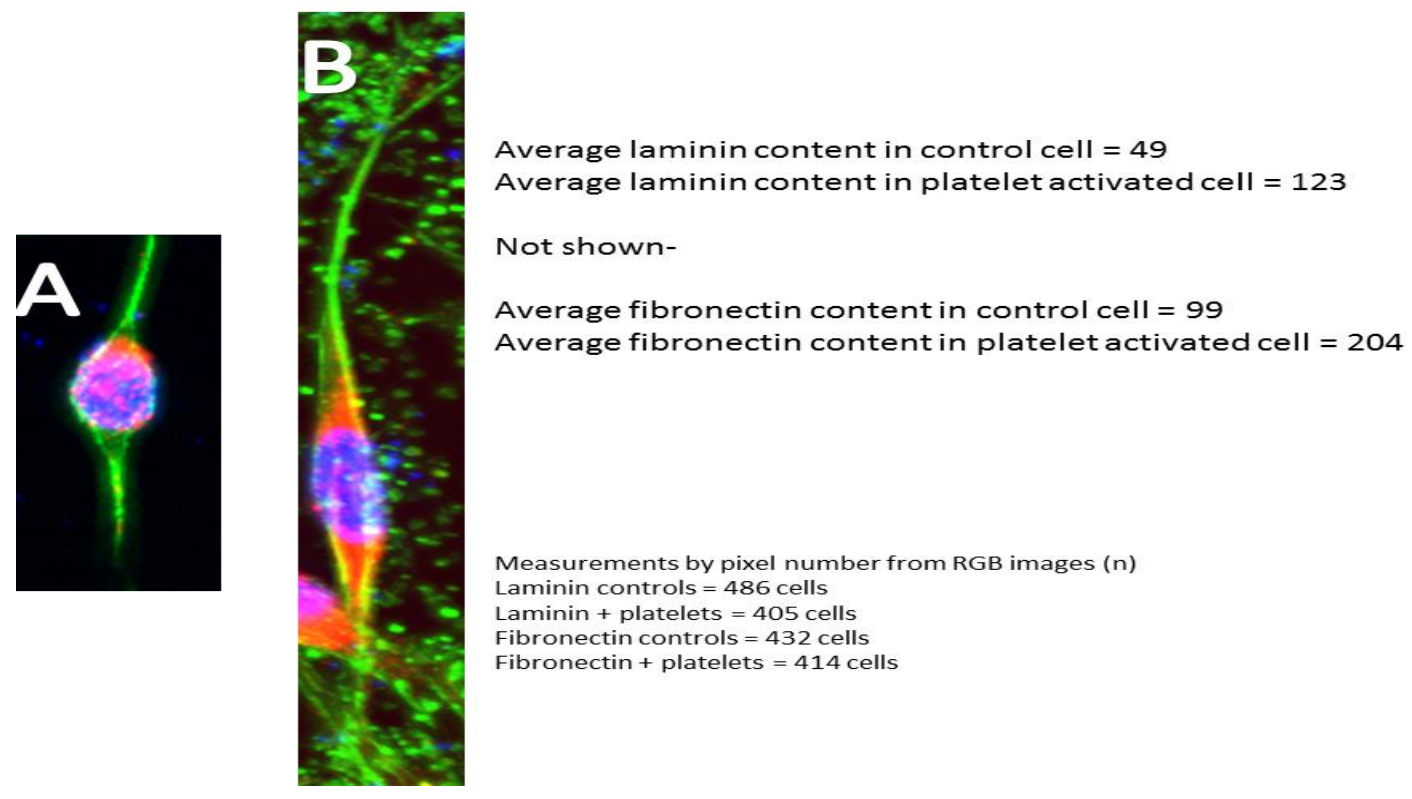

Fig. 2. A bulbous control cancer cell (image A) compared to a long, slender, mesenchymal-like, platelet treated cell (image B). Probing these cultures for laminin and fibronectin content in the cultures revealed dramatic increases in protein, with doubling of the protein content in platelet treated cells. Fluorescent images for laminin are shown here. Quantities as measured by pixel densities are noted in the image, together with number of cells counted. (mag x. 1800: minimum of 300 cells: $p$ values for all comparisons $<0.05$ )

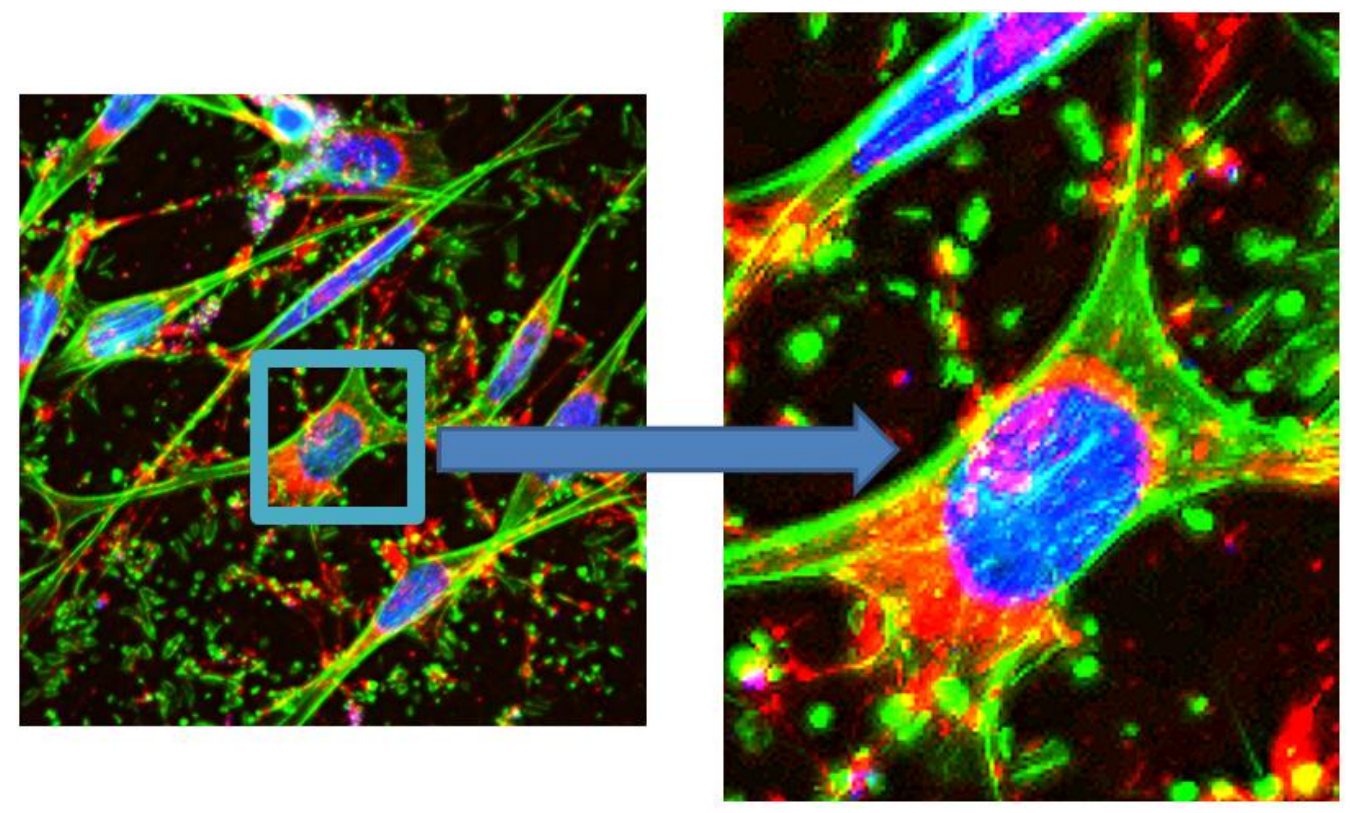

Fig. 3. Intense red/orange staining is seen in the perinuclear area of cells (likely golgi and endoplasmic reticulum. Mag. $x$ 1200) co-cultured with platelets (high magnification cut-out also shown mag. $x$ 2400), while some extracellular fibronectin can also be seen. Modeling of protein to yield an image with a greater degree of clarity as to intracellular locations was performed as referenced in Results section 

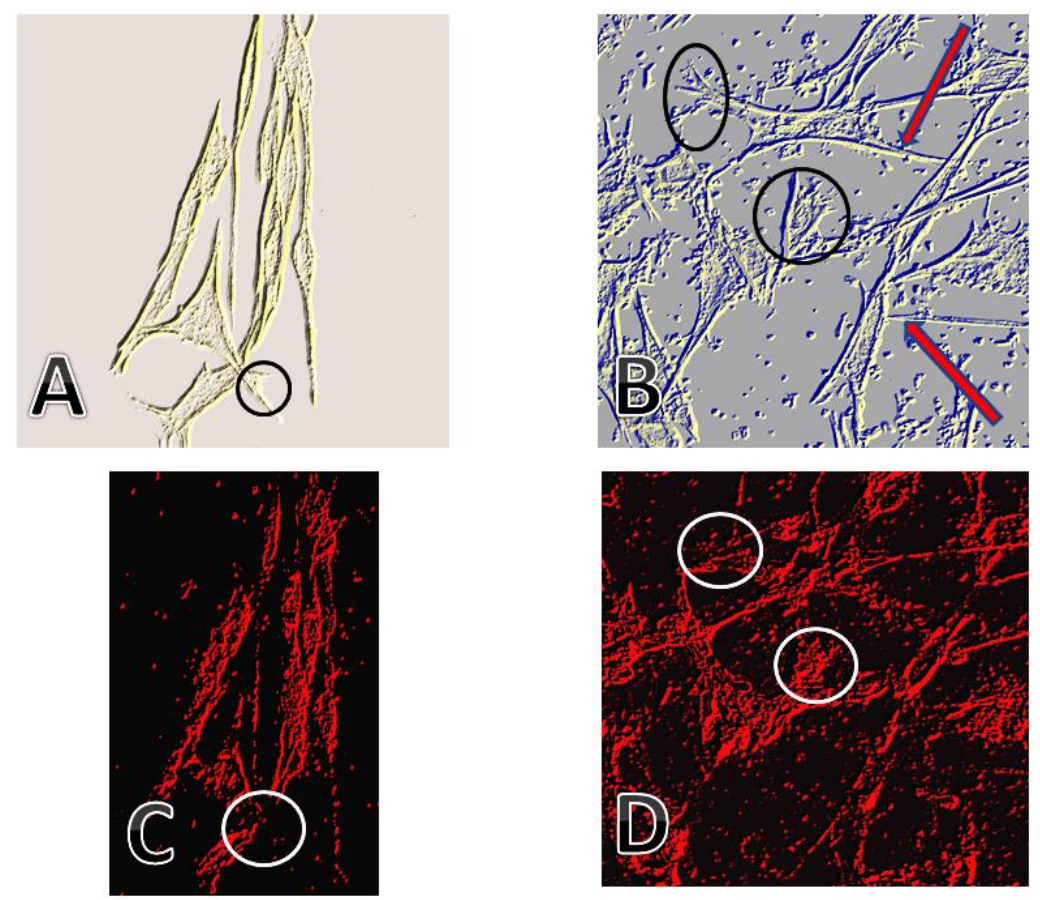

Fig. 4. Channel splitting of control (A and $C)$ and platelet co-cultured cells (B and D). Black circles indicate areas of adhesion in images $A$ and $B$, coupled with arrows indicating long fibronectin fibers in the platelet-added culture (B). When the images were mapped with the specific probe wavelength assigned to the protein (lower red images; images $C$ and $D$ ), the control cells do not have fibronectin in some adhesion areas (C), unlike the platelet treated culture (D) which has a copious amount of fibronectin in areas of stellate projections (white circles). Embossed, stacked images as referenced in Methods
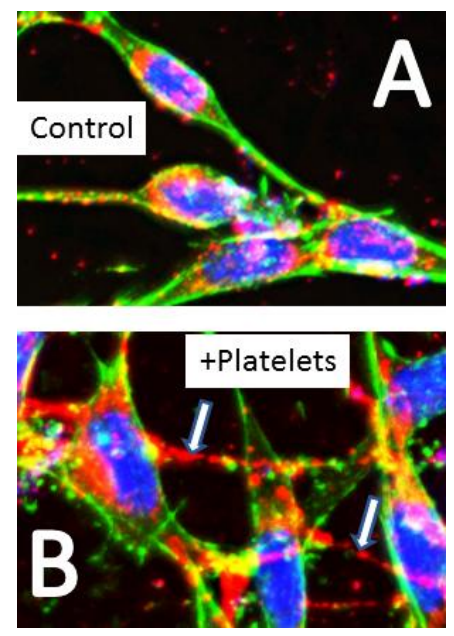

Fig. 5. Expanded images of a cultured cell image (Panel A) versus platelet activated cells (Panel $B$ ) to show extracellular

extensions (white arrows) in Panel B, compared to panel A (Control cells) where most of the fibronectin is intracellular (final mag. $x$ 3000)

\section{DISCUSSION}

Platelets promote the transformation of cells in early dysplasia, an important stage for the development of cellular invasive abilities as well as attachment and growth in tissues and organs. Platelets are also intimately involved in thrombosis in late-stage cancer patients, so these anuclear products of megakaryocytes have become a primary target in the anti-inflammatory medication treatment of cancer [22] due to cellular changes occurring with the release of a number of mediators, particularly platelet-derived growth factor (PDGF), vascular endothelial growth factor (VEGF) and TGF $\beta[23,24,25]$. A number of investigators have therefore studied platelets as a possible target for non-steroidal anti-inflammatory drugs (NSAIDs) treatment in cancer via an irreversible inhibition of COX-1 activity and arrested EMT $[26,27,18]$. Our results demonstrate that platelets promote the growth and invasive potential of mouse (MC-26) colon cancer cells, confirming the findings of Labelle and colleagues [28], and that these robust, 
platelet-dependent cellular and biochemical changes are protein specific, strongly suggesting that platelets up-regulate protein syntheses to increase the invasive and adhesive potential of colon cancer cells, something we have also found with a human colon cell line and human platelets.

In vivo studies in mice with an established model of colon cancer $[29,30]$ demonstrated that platelets migrated into inflamed colonic mucosa and adjacent tumor tissue, associating with the vasculature and surrounding mucosal inflammation and dysplasia. This observation lends more weight to earlier findings regarding the multiple roles of platelets in many diseases [31]. Further evidence for platelet multifunctioning was reported in a recent study by Qi et al. [32] who noted the presence of platelets in intestinal tumors from APC Min mice and from clinical biopsies of patients with colorectal cancer (CRC), while both the Qi study and a study from Miyashita et al. [33] showed platelet extravasation into the invasive front of pancreatic ductal adenocarcinomas.

Platelets are therefore intimately involved in the progression of cancer, which strongly suggests that blocking platelet cell transition effect(s) must be considered a target for treatments, especially given the well documented cardiovascular benefits of aspirin [34], and recent reports of positive outcomes with aspirin in patients with pancreatic [35] and colorectal cancer [36]. The benefits of aspirin in cancer treatment have been reported [36] and it is therefore important that we understand both the structural and biochemical signaling of epithelial cells as they become invasive and life-threatening.

Low-dose aspirin, sufficient enough to block platelet-cancer cell interactions which play a fundamental role in cancer formation and progression, might have a limited antiinflammatory activity but could be a useful part of a treatment regimen [37], especially as aspirin has been shown to inhibit platelet induced cancer cell proliferation [38] and have a good outcome regarding previous cancers [39]. Thus, halting the expression of fibronectin and other matrix proteins via platelet inactivation, could become a major aspect of the fight against cancer, and follows many years of studies which reported the role of fibronectin in cell adhesion and the lack of deposition by malignant cells into a matrix [39]. A more recent report of the importance of fibronectin and its receptors in tumor development and matrix development [40] has stressed the role of this protein, such that our results implicate that increased fibronectin synthesis is initiated to facilitate cell invasion into and adhesion within the underlying matrix, moving the process away from basement membrane laminin formation. This points to these two proteins having specific and divergent roles in cancer and colonization and might be considered as targets for treatment options, together with NSAIDS and the manipulation of cyclo-oxygenase $[41,42,43,44]$. Aspirin is now recognized as being at least a potential adjunct in anti-cancer therapy. This is not only due to its anti-inflammatory abilities, but also to its now well recognized anti platelet interactions. Couple these properties with other reported positives $[38,39]$, and using the drug to down regulate matrix protein formation, might provide a welltolerated therapeutic strategy.

\section{FUTURE DIRECTIONS}

Further studies need to be made with other forms of cancer, both those that are somewhat slow in mechanism and those that are aggressive in nature, in order to see if aspirin can overcome rapid EMT and the formation of matrix component proteins. Further, experiments must be performed to see how and where aspirin and platelets are involved in extravasation, hopefully halting metastatic growths. Our desire to delve into the pathways and mechanisms as to why mesenchymal transformations are exacerbated by platelets and, to some extent at least, halted by aspirin, has led to initial experiments being performed with breast cancer cells and an aggressive pancreatic cancer, in conjunction with colleagues at MD Anderson Cancer Center.

\section{CONCLUSION}

Our work investigating anti-inflammatories and anti-neoplastic actions via irreversible COX-1 inhibition shows promise, but how platelets activate cells and how subsequent EMT leads to cells becoming invasive and accruing abilities that makes them mobile, are mechanisms that need more understanding. To add more clarity to cell transitions, we are looking at the synthesis and the form of proteins to determine if there are other, as yet uncovered, pathways that could be a focus for stopping cells from escaping the vasculature and lymphatics and undergoing changes which yield multi-potential mesenchymal cells. 


\section{CONSENT}

Consent is not needed in this study. No patient tissues or fluids used.

\section{ETHICAL APPROVAL}

All authors hereby declare that "Principles of laboratory animal care" (NIH publication No. 8523, revised 1985) were followed, as well as specific national laws where applicable. All experiments have been examined and approved by the appropriate ethics committee. All experiments have been examined and approved by the appropriate ethics committee and have therefore been performed in accordance with the ethical standards laid down in the 1964 Declaration of Helsinki."

\section{COMPETING INTERESTS}

Authors have declared that no competing interests exist.

\section{REFERENCES}

1. Honn KV, Tang DG, Crissman JD. Platelets and cancer metastasis: A causal relationship? Cancer Metastasis Reviews. 1992;11(3-4):325-351.

2. McCarthy JB, Furcht LT. Laminin and fibronectin promote the haptotactic migration of B16 mouse melanoma cells in vitro. Journal of Cell Biology. 1984; 98(4):1474-1480.

3. Flier $\mathrm{SN}$, Tanjore $\mathrm{H}$, Kokkotou EG, Sugimoto $H$, Zeisberg $M$, Kalluri $R$. Identification of epithelial to mesenchymal transition as a novel source of fibroblasts in intestinal fibrosis. Journal of Biological Chemistry. 2010;285(26):20202-20212.

4. Potenta S, Zeisberg M, Kalluri R. The role of endothelial-to-mesenchymal transition in cancer progression. British Journal of Cancer. 2008;99(9):1375-1379.

5. Wang $Y$, Zhou BP. Epithelial-mesenchymal transition - A hallmark of breast cancer metastasis. Cancer Hallmarks. 2013;1(1): 38-49.

6. Mitrugno A, Tormoen GW, Kuhn P, McCarty OJ. The prothrombotic activity of cancer cells in the circulation. Blood Reviews. 2016;30(1):11-19.

7. Salgado R, Benoy I, Bogers J, Weytjens R, Vermeulen $P$, Dirix L, Van Narck $E$. Platelets and vascular endothelial growth factor (VEGF): A morphological and functional study. Angiogenesis. 2001; 4(1):37-43.

8. Kirwan CC, Byrne GJ, Kumar S, McDowell G. Platelet release of vascular endothelial growth factor (VEGF) in patients undergoing chemotherapy for breast cancer. Journal of Angiogenesis Research. 2009;1:7.

9. Labelle M, Begum S, Hynes RO. Direct signaling between platelets and cancer cells induces an epithelial-mesenchymallike transsition and promotes metastasis. Cancer Cell. 2011;20(5):576-590.

10. Yu Y, Zhou XD, Liu YK, Ren N, Chen J, Zhao Y. Platelets promote the adhesion of human hepatoma cells with a highly metastatic potential to extracellular matrix protein: Involvement of platelet P-selectin and GP Ilb-IIla. Journal of Cancer Research and. Clinical Oncology. 2001; 128(2):283-287.

11. Martin TA. The role of tight junctions in cancer metastasis. Seminars in Cell Development and Biology. 2014;36:224231.

12. Martin TA, Ye L, Sanders AJ, Lane J, Jiang WG. Cancer invasion and metastasis: Molecular and cellular perspective. Metastatic cancer: Clinical and biological perspectives edited by Rahul Jandial. Landes Bioscience. In: Madame Curie Bioscience Database [Internet]; 2013. Austin (TX).

Available:http://www.ncbi.nlm.nih.gov/book s/NBK164700/

(Accessed January $2^{\text {nd }}, 2017$ )

13. Nistico $P$, Bissell MJ, Radisky DC. Epithelial-mesenchymal transition: General principles and pathological relevance with special emphasis on the role of matrix metalloproteinases. Cold Spring Harbor Perspectives in Biolgy. 2012;4(2).

14. Zeisberg M, Neilson EG. Biomarkers for epithelial-mesenchymal transitions. Journal of Clinical Investigation. 2009;119(6):14291437.

15. Nieto MA, Huang RY, Jackson RA, Thiery, JP. EMT: Cell. 2016;166(1):21-45.

16. Bynagari $\mathrm{YS}$, Nagy $\mathrm{B} \mathrm{Jr}$, Tuluc $\mathrm{F}$, Bhavaraju K, Kim S, Vijayan KV, Kunapuli SP. Mechanism of activation and functional role of protein kinase Ceta in human platelets. Journal of Biological Chemistry. 2009;284(20):13413-13421.

17. Khatlani T, Pradhan S, Da Q, Gushiken $\mathrm{FC}$, Bergeron AL, Langlois KW, et al. The beta isoform of the catalytic subunit of 
protein phosphatase $2 \mathrm{~B}$ restrains platelet function by suppressing outside-in all $b$ beta3 integrin signaling. Journal of Thrombosis and Haemostasis. 2014; 12(12):2081-2101.

18. Poindexter BJ, Frazier OH, Bick RJ. Fluorescence Deconvolution Microscopy and cellular modeling to understand heart repair as a result of ventricular unloading: cell culture to LVAD. International Journal of Cardiovascular Research. 2015;4:6.

19. Lichtenberger LM, Fang D, Bick RJ Poindexter BJ, Phan T, Bergeron AL, et al. Unlocking aspirin's chemopreventive activity: Role of irreversibly inhibiting platelet COX-1. Cancer Prevention Research. 2017;10(2):142-152.

20. Bick RJ, Poindexter, BJ, Bates, ST, Gemmato, CJ, Frazier, OH, Evans PM. Fluorescence Deconvolution Microscopy and cellular modeling to understand heart repair after ventricular unloading. Microscopy: Science, Technology, Applications and Education. 2011;1:705709. (Eds. Antonio Menendez-Vilas, Jesus Diaz Alvarez. Published by Formatex Research Center).

21. Doursout MF, Schiess MC, Schurdell MS, Osuagwu U, Hook DM, Poindexter BJ, et al. Specific localizations of cytokines and Parkinson's disease-associated proteins revealed by fluorescence deconvolution microscopy in brain tissues of an LPS treated rat model. Current Trends in Neurology. 2013;2:39-49.

22. Franco AT, Corken A, Ware J. Platelets at the interface of thrombosis, inflammation and cancer. Blood. 2015;126(5):582-588.

23. Kuzet SE, Gaggioli C. Fibroblast activation in cancer: when seed fertilizes soil. Cell Tissue Research. 2016;365(3):607-619.

24. Suri A, Sheng $X$, Schuler KM, Zhong $Y$, Han $X$, Jones HM, Gehrig PA, Zhou C, Bae-Jump VL. The effect of celecoxib on tumor growth in ovarian cancer cells and a genetically engineered mouse model of serous ovarian cancer. Oncotarget. 2016; 7(26):39582-39594.

25. Kim J, Kong J, Chang H, Kim H, Kim A. EGF induces epithelial-mesenchymal transition through phosph-Smad2/3-Snail signaling pathway in breast cancer cells. Oncotarget. 2016;7(51):8502185032.

26. Trabert $B$, Ness RB, Lo-Ciganic WH, Murphy MA, Goode EL, Poole EM, et al. Australian ovarian cancer study
Group, Australian Cancer Study (Ovarian Cancer), Risch HA, Rossing MA, Doherty JA, Goodman MT, Lurie G, et al. Ovarian Cancer Association Consortium. Aspirin, nonaspirin nonsteroidal anti-inflammatory drug, and acetaminophen use and risk of invasive epithelial ovarian cancer: A pooled analysis in the Ovarian Cancer Association Consortium. Journal of The National Cancer Institute. 2014; 106:djt431.

27. Gamba CA, Swetter SM, Stefanick ML, Kubo J, Desai M, Spaunhurst KM, et al. Aspirin is associated with lower melanoma risk among postmenopausal Caucasian women: The Women's Health Initiative. Cancer. 2013;119(8):1562-1569.

28. Labelle M, Begum S, Hynes RO. Direct platelet interactions promote tumor cell metastasis Cancer Discovery. 2012;2;1-9.

29. Cho MS, Bottsford-Miller J, Vasquez HG, Stone R, Zand B, Kroll MH, et al. Platelets increase the proliferation of ovarian cancer cells. Blood. 2012;120(24):4869-4872.

30. Clapper ML, Cooper HS, Chang WC. Dextran sulfate sodium-induced colitisassociated neoplasia: a promising model for the development of chemopreventive interventions. Acta Pharmacol Sin. 2007; 28(9):1450-59.

31. Stokes KY, Granger DN. Platelets: A critical link between inflammation and microvascular dysfunction. Journal of Physiology. 2012;590(5):1023-1034.

32. Qi C, Li B, Guo S, Wei B, Shao C, Li J, et al. P-selectin-mediated adhesion between platelets and tumor cells promotes intestinal tumorigenesis in $\mathrm{Apc}(\mathrm{Min} /+)$ mice. International Journal of Biological Science. 2015;11(6):679-687.

33. Miyashita $\mathrm{T}$, Tajima $\mathrm{H}$, Makino I, Nakagawara $H$, Kitagawa $H$, Fushida $S$, et al. Metastasis-promoting role of extravasated platelet activation in tumor. Journal of Surgical Research. 2015; 193(1):289-294.

34. Agus DB, Gaudette E, Goldman DP, Messali A. The long-term benefits of increased aspirin use by at-risk americans aged 50 and older. PLoS One. 2016; 11(11):e0166103.

35. Risch HA, Lu L, Streicher SA, Wang J, Zhang $\mathrm{W}$, Ni Qetal. Aspirin use and reduced risk of pancreatic cancer. Cancer Epidemiology, Biomarkers and Prevention. 2017;26(1):68-74. 
36. Bui QM, Lin D, Ho W. Approach to Iynch syndrome for the gastroenterologist. Digestive Disorders Science. 2016; 62(2):299-304.

37. Santilli F, Boccatonda A, Davi G. Aspirin, platelets, and cancer: The point of view of the internist. Europena Journal of Internal Medicine. 2016;34:1120.

38. Mitrugno A, Sylman JL, Ngo AT, Pang J, Sears RC, Williams CD, McCarthy OJ. Aspirin therapy reduces the ability of platelets to promote colon and pancreatic cancer cell proliferation: Implications for the oncoprotein cMYC. American Journal of Physiology; Cell Physiology. 2017; 312:C176-189.

39. Dulai PS, Singh S, Marquez E, Khera R, Prokop LJ, Limburg PJ, Gupta S, Murad $\mathrm{MH}$. Chemoprevention of colorectal cancer in individuals with previous colorectal neoplasia: Systemic review and network meta-analysis. British Medical Journal. 2016;5(355):i16188.
40. Ruoslahti E. Fibronectin in cell adhesion and invasion. Cancer Metastasis Reviews. 1984;3(1):43-51.

41. Ruoslahti E. Fibronectin and its integrin receptors in cancer. Advances in Cancer Research. 1999;76(1):1-20.

42. Ramovs $\mathrm{V}$, te Molder $\mathrm{L}$, Sonnenberg $\mathrm{A}$. The opposing roles of laminin-binding integrins in cancer. Matrix Biology. 2017; 57-58:213-243.

43. Yi W, Xiao E, Ding R, Luo P, Yang Y. High expression of fibronectin is associated with poor prognosis, cell proliferation and malignancy via the NF-kB/p53-apoptosis signaling pathway in colorectal cancer. Oncology Research. 2016;36(6):31453153.

44. Ito $H$, Duxbury $M$, Benoit $E$, Farivar RS, Gardner-Thorpe J, Zinner MJ, et al. Fibronectin-induced COX-2 mediates MMP-2 expression and invasiveness of rhabdomyosarcoma. Biochemical and Biophysical Research Communications. 2004;318(2):594-600.

(c) 2017 Poindexter et al.; This is an Open Access article distributed under the terms of the Creative Commons Attribution License (http://creativecommons.org/licenses/by/4.0), which permits unrestricted use, distribution, and reproduction in any medium, provided the original work is properly cited.

Peer-review history:

The peer review history for this paper can be accessed here: http://sciencedomain.org/review-history/19551 